\title{
Sambandet mellan fysisk sjukdom och suicid hos äldre
}

Ved M argda W ærn

I takt med att allt fler uppnår hög ålder förväntas antalet självmord stiga. En förutsättning för prevention av självmord hos äldre är en ökad förståelse kring varför äldre människor tar sina liv. Kroppslig sjukdom kan leda till funktionsnedsättning, autonomiförlust, och suididalitet. Denna artikel behandlar sambandet mellan fysisk sjukdom och suicid hos äldre. Resultat från några lovande interventionsstudier presenteras.

\section{Bakgrund}

Ä Idre har höga självmordstal i de flesta industriländer. Eftersom den äldre befolkningen växer förväntas suicid att rankas som nummer tio bland de vanligaste dödsorsakerna i världen år 2020 ( M urray \& Lopez 1997). De nordiska länderna har på senare år utvecklat nationella program för självmordsprevention. $M$ an noterar att de äldre utgör en eftersatt riskgrupp. En förutsättning för prevention av självmord hos denna åldersgrupp är en ökad förståelse kring varför äldre människor tar sina liv.

A tt depression utgör en mycket kraftig riskfaktor för självmord bland äldre är välbekant (för en färsk översikt se 0 'C onnell et al. 2004). Det har till och med uppskattats att $74 \%$ av den al Ivarliga suicidaliteten hos äldre skulle försvinna om depressionerna behandlades framgångsrikt (Beautrais 2002). M en hos många äldre kompliceras bilden av att det samtidigt förekommer depression och handikappande kroppslig sjukdom. U tgör fysisk sjukdom en oberoende riskfaktor för suicid hos äldre? Vi sökte svar på denna fråga när vi la upp vår studie kring själ vmord bland äldre. Studien, som ägde rum i V ästsverige, var den första i sitt slag. Ä ven kontroller från befolkningen deltog, vilket gjorde det möjligt för oss att uppskatta självmordsrisk vid olika typer av fysiska sjukdomar.

\section{Självmord bland äldre i Västsverige: en fall- kontrollstudie}

Etthundra fall av självmord bland äldre individer i V ästsverige granskades. A nhöriga till 85 fall (46 män, 39 kvinnor) accepterade att delta i intervjuundersökningen. Suidcidfallen var i åldrarna 65 - 97 år med medianålder 75 år. A nhörigintervjuerna utfördes av en psykiater och följdes upp av en tel efonintervju med en socionom. G enom intervjuerna har vi försökt att skapa en bild av hur livssituationen gestaltade sig under tiden före döden. Intervjun inkluderade bland annat frågor kring individens kroppsliga och psykiska hälsa, sjukvårdskontakter, medicinering och social situation.

Kontrol lgruppen hade samma sammansättning som självmordsgruppen beträffan de kön, födel seår och bostadsort. Av 234 tillfrågade tackade 153 kontrollpersoner ja till undersökningen. Individerna i kontrollgruppen intervjuades i hemmet, med samma intervjuprotokoll som ovan.

\section{Hur kan man få ett mått på fysisk sjukdomsbörda?}

Intervjudata för både fallen och kontrollpersonerna kompletterades med information från sjukvårdsjournaler, och individens hälsa skattades enligt $C$ umulative IIIness R ating Scale - G eriatrics (CIRS-G), en skala specialdesignad att mäta sjukdomsbörda hos äldre personer (M iller et al. 1992). Skalan ger operationaliserade mått på sjukdomsgrad (0-4) för 13 somatiska organsystem. I vår studie definierades allvarlig fysisk sjukdom som en 3 (allvarliga symtom/signifikant funktionsnedsättning) eller 4 (mycket allvarliga symtom/mycket allvarlig funktionsnedsättning) i någon organkategori. Vi räknade också fram total sjukdomsbörda.

\section{Fysisk sjukdom var en oberoende riskfaktor}

Som framgår av Tabell 1 var neurologiska sjukdom och ögon, öron, näsa, hals problem vanligare hos självmordsgruppen än hos kontrollgruppen. C ancersjukdom (i vilken organkategori som helst) gav en tredubblad risk för självmord.

\begin{tabular}{|c|c|c|c|c|c|c|}
\hline Organ Kategori & $\mathbf{n}$ & (\%) & $\mathbf{n}$ & $(\%)$ & OR & (95\% KI) \\
\hline Hjärta & 8 & (9.4) & 15 & (9.8) & 1.0 & $(0.4-2.5)$ \\
\hline Kärl & 4 & (4.7) & 6 & (3.9) & 1.1 & $(0.3-4.0)$ \\
\hline Blod & 1 & (1.2) & 1 & $(0.7)$ & 3.2 & $(0.2-53.9)$ \\
\hline Lungor & 2 & $(2.4)$ & 5 & (3.3) & 0.7 & $(0.1-3.5)$ \\
\hline Ö gon, öron, näsa, hals & 15 & $(17.6)$ & 9 & (5.9) & 6.6 & $(2.4-17.9)$ \\
\hline Synnedsättning & 12 & (14.1) & 6 & (3.9) & 7.0 & $(2.3-21.4)$ \\
\hline Ö vre magtarmkanal & 2 & $(2.4)$ & 1 & $(0.7)$ & 6.4 & $(0.5-79.2)$ \\
\hline N edre magtarmkanal & 4 & $(4.7)$ & 4 & (2.6) & 3.3 & $(0.7-14.8)$ \\
\hline N jurar & 1 & (1.2) & 1 & $(0.7)$ & 2.2 & $(0.1-39.7)$ \\
\hline U rogenenitalt & 8 & $(9.4)$ & 10 & $(6.5)$ & 3.0 & $(1.0-9.0)$ \\
\hline M uskel/skelett & 12 & (14.1) & 24 & (15.7) & 1.6 & $(0.7-3.9)$ \\
\hline Endokrint/metabolt & 6 & $(7.1)$ & 3 & $(2.0)$ & 2.7 & $(0.6-11.4)$ \\
\hline N eurologi & 15 & (17.6) & 10 & (6.5) & 3.8 & $(1.5-9.4)$ \\
\hline Stroke & 9 & (10.6) & 7 & $(4.6)$ & 2.8 & $(1.0-8.3)$ \\
\hline Cancer** & 9 & (10.6) & 8 & $(5.2)$ & 3.4 & $(1.2-9.8)$ \\
\hline
\end{tabular}


$\mathrm{N}$ ågon form av allvarlig fysisk sjukdom konstaterades hos $55 \%$ av självmordsfallen (Figur 1). För individerna i kontrollgruppen var andelen 39\%. A llvarlig kroppslig sjukdom var associerat med en trefaldig ökning av suicidrisk. Fysisk sjukdom kvarstod som riskfaktor för suicid, även efter justering för depression (Waern et al. 2002).

Figur 1. Allvarlig fysisk sjukdom hos suicidfall och kontroller.

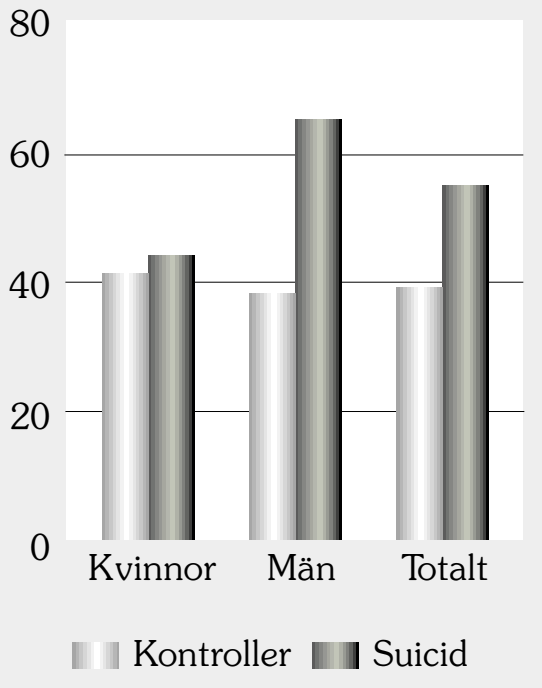

$\mathrm{N}$ är data för kvinnor och män analyserades för sig så visade det sig att allvarlig somatisk sjukdom var en riskfaktor för män, men inte för kvinnor. Hög total sjukdomsbörda ( summan av skattningar på samtliga organkategorier> 10) var också associerat med suicid hos män (W aern et al. 2002). Det är dock möjligt att dessa könsskillnader endast var skenbara eftersom antalet kvinnor i studien var relativt litet.

\section{Vad säger fall-kontrollstudier från andra länder?}

Conwell och kollegor jämförde förekomsten av fysisk sjukdom hos suicidfall $(60+)$ och kontrollpersoner som sökt primärvård (C onwell et al 2000). Femtiofem procent av självmordsfallen hade någon allvarlig fysisk sjukdom, en siffra mycket snarlik den rapporterade från vår egen studie (55\%) . A llvarlig fysisk sjukdom fannsendast hos 16\% av personerna i kontrollgruppen. Studien kunde dock inte klargjora huruvida fysi sk sjukdom ut- gjörde en oberoende riskfaktor. En senare studie, från samma geografisk område visade att fysisk sjukdom var kopplad till ökad risk för suicid, och risken kvarstod även efter man tagit hänsyn till förekomsten av psykiska sjukdomar (Duberstein et al 2004). D et finns dock en fall-kontrollstudie som inte fann någon ökning av suicid bland äldre personer med fysisk sjukdom (Beautrais 2002). A ndelen av suicidfallen med allvarlig fysisk sjukdom i denna studie från $\mathrm{N}$ ya Zeeland var endast $26 \%$. En möjlig förklaring kan vara den relativt unga åldern hos fallen ( 55 år och uppåt).

\section{Registerdata bekräftar risken med fysisk sjukdom}

Behov av sjukhusvård kan ses som en sjukdomsindikator. Erlangsen och kollegor studerade Danmarks nationella patientregister och konstaterade att sjukhusvård för somatiska diagnoser var associerat med ökad suicidrisk (Erlangsen et al. 2003). $\mathrm{N}$ ästan två tredjedelar av de äldsta ( $80+)$ som suiciderade hade legat inne för somatisk vård under två-årsperioden som föregick självmordet.

Ett annat sätt att studera sjukdomsbörda hos olika grupper är att studera deras läkemedelsförbrukning. I C anada registreras samtliga recept på individnivå, varför man där kan använda receptförskrivningsdata som sjukdomsindikator. Juurlink och kollegor (Juurlink et al. 2004) identifierade 17 olika läkemedel som kunde betraktas som markörer för specifika sjukdomstillstånd. Som ett exempel, om en person hade fått recept för inhalationsbehandling med steroider, drog man slutsatsen att personen led av kronisk lungsjukdom. Efter genomgång av recept utskrivna till 1329 suicidfall och 5315 befolkningskontroller konstaterade man att behandling mot kronisk obstruktiv lungsjukdom, hjärtsvikt, urininkontinens, epilepsi och smärta var samtliga associerade med självmord. Vidare konstaterade forskargruppen att ju flera läkemedel, desto högre var risken för självmord.

\section{Frågar läkare efter suicidalitet?}

G enom olika typer av forskningsansatser har man således fått fram otvetydigt bevis på att fysisk sjukdom ökar risken för suicid hos äldre. M en frågar läkare efter suicidalitet när äl dre söker för fysiska krämpor? En genomgång av journal handlingar inom ramen för den västsvenska studien visade att endast en tredjedel av självmordsfallen hade förmedlat någon form av suicidalitet till sin doktor under året som föregick suicidet (W aern et al. 1999). Det var ovanligt att frågor om dödsönskan och självmordstankar togs upp under konsultationer med patienter som led av allvarlig kroppslig sjukdom eller syn-, hörsel- eller rörelsehandikapp. Det finns således ett behov av interventioner som syftar till identifiera och behandla fysiskt sjuka äldre med suicidtankar. Ett par lovande exempel redovisas nedan.

\section{En primärvårdsintervention för äldre}

Syftet med PROSPECT (Prevention of Suicide in Primary Care Elderly: Collaborative Trial) var att minska förekomsten av riskfaktorer för självmord hos personer 60 år och äldre (Bruce et al. 2004). T jugo primärvårdsmottagningar i östra U SA deltogi studien. Hälften randomiserades till en intervention bestående av två komponenter: 1) en klinisk algoritm för behandling av äldredepressioner, med ett SSRI som förstahandsmedel, och 2) en "depression care manager". Den andra hälften fick sedvanlig vård. M ed stöd av psykiater följde denna specialutbildade kurator/sjuksköterska/psykolog patienten med avseen de på symtom, biverkningar och komplians. Patienter som avböjde läkemedel sbehan dling erbjöds interpersonell psykoterapi.

G enom screening av ett slumpmässigt urval av patienterna kunde de med depressionssymtom identifieras. Därefter rekryterades 598 patienter med klinisk signifikant depression. Suicidalitet skattades med Beck's Suicidal Ideation Scale och depressionsgraden med $\mathrm{H}$ amilton Depression Rating Scale (HRDS) initialt samt vid 4, 8 och 12 månader. 
Interventionsgruppen förbättrades snabbare än de som erhöll sedvanlig vård. Vid 8 månader hade suicidaliteten minskat med $71 \%$ hos interventionspatienterna och med 44 \% hos kontrollgruppen. Även depressionsgraden minskade snabbare hos interventionsgruppen. En kommande publikation skall fokusera på bl.a. hälsoekonomiska aspekter. Redan nu antyder fynden att "depressionsspecialister" kan förbättra vården av äldre som tappat livsgnistan.

\section{En psykosocial intervention}

Ett interventionsprojekt som ägt rum i norra Italien har uppmärksammats. Syftet var inte direkt att minsta antalet självmord i området utan att bryta isolering hos somatiskt sjuka, funktionshindrade äldre (De Leo et al. 2002). Interventionen består av två delar: dels kontakt två gånger per vecka via en telefonhjälplinje (Telecheck) och dels en dygnetrunt alarmtjänst (Telehelp). I en utvärdering jämfördes förekomst av självmord bland 18641 Telecheck/Telehelp användare med förekomsten hos befolkningen i ett annat område som saknade interventionen. Färre självmord registrerades i interventionsområdet. Liksom vid Gotlandsprojektet minskade självmord mer bland kvinnor än bland män under projekttiden.

\section{Konklusion}

Fysisk sjukdom är kopplade till en ökad risk för självmord hos äldre. Möjligtvis är kopplingen starkare för män än för kvinnor. Mer forskning behövs för att belysa detta och för att få fram interventioner som kan minska suicidalitet hos äldre vars liv och livslust begränsas av somatiska åkommor.

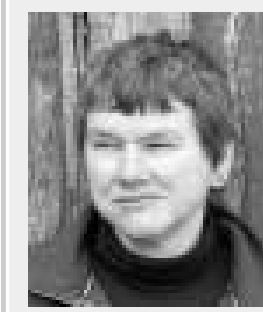

M argda W ærn är psykiater och docent vid Institutionen för klinisk neurovetenskap, Sahlgrenska akademin vid Göteborgs universitet. Hon disputerade 2000 med avhandlingen

Suicide in Late Life.

Aktuella forskningsprojekt inkluderar riskfaktorer för suicidförsök hos äldre, prediktorer av behandlingsresistent suicidalitet, samt projektet kvinnor, alcohol och suicidalitet.

\section{Referenser}

Beautrais A. A case control study of suicide and attempted suicide in older adults. Suicide and Life-Threatening Behavior 2002; 32(1):1-9.

Bruce ML, Ten Have TR, Reynolds CF $3^{\text {rd }}$, Katz II, Schulberg HC, Mulsant BH, Brown GK, McAvay GJ, Pearson JL, Alexopoulos GS. R educing suicidal ideation and depressive symtoms in depressed older primary care patients: a randomized controlled trial. Journal of the American Medical Association 2004; 291:1081-91.

Conwell Y, Lyness JM, Duberstein P, Cox C, Seidlitz L, DiGiorgio A, Caine E. C ompleted suicide among older patients in primary care practices: A controlled study. Journal of the American Geriatrics Society 2000;48:23-29.

De Leo D, Dello Buono M, Dwyer J. Suicide among the elderly: the long-term impact of a telephone support and assessment intervention in northern Italy. British Journal of Psychiatry 2002;181:226-9.

Duberstein P, Conwell Y, Conner KR et al. Suicide at $\mathbf{5 0}$ years and older: perceived physical illness, family discord and financial strain. Psychological Medicine 2004;34:137-146.

Erlangsen A, Vach W, Jeune B. T he impact of hospitalisation with somatic diagnoses on the suicide risk among the oldest old: a populationbased register study. In: Disparities in Suicide among the old and oldest old in Denmark (PhD thesis). Odense: University of Southern Denmark, 2003.

Juurlink DN, Hermann N, Szalai JP, Kopp A Redelmeier DA. Medical illness and the risk of suicide in the elderly. Archives of Internal Medicine 2004;164:1171-2

Miller MD, Paradis CF, Houck PR, Mazumdar S, Stack JA, Rifai AH, Mulsant B, Reynolds CF, $3^{\text {rd }}$ $R$ ating chronic medical illness burden in geropsychiatric practice and research: application of the $\mathbf{C}$ umulative IIIness $\mathbf{R}$ ating Scale. Psychiatry Research 1992;41: 237-248.

Murray CJ, Lopez AD. A Iternative projections of mortality and disability by cause 1990-2020:

G lobal B urden of D isease Study. Lancet 1997; 349:1498-504.

O'Connell H, Chin A-V, Cunningham C, Lawlor BA. R ecent developments: Suicide in older people. British Medical Journal 2004;329:895-899.

Waern M, Beskow J, Runeson B, Skoog I. Suicidal feelings in the last year of life in elderly people who commit suicide. Lancet 1999;354:917-918.

Waern M, Rubenowitz E, Runeson B, Skoog I, Wilhelmson K, Allebeck P. Illness burden in elderly suicides: A controlled study. British Medical Journal 2002;324:1355-1358.

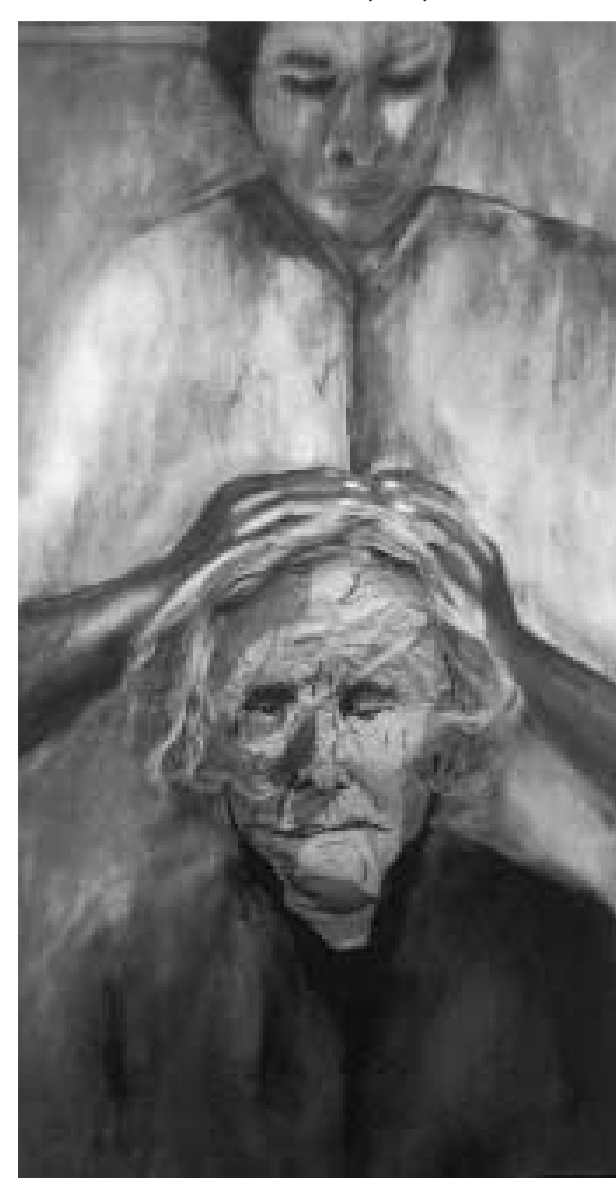

